\title{
Pro-environmental Behavior Regarding Solid Waste Management in Householders of Kalutara Urban Council Area: A Case Study
}

\author{
S.R. Amarasinghe ${ }^{1 *}$ and F.F.H.G. Fernando ${ }^{2}$ \\ ${ }^{1}$ Department of Soil Science, Faculty of Agriculture, University of Ruhuna, Sri Lanka \\ ${ }^{2}$ National Water Supply and Drainage Board, Water Treatment Plant, Kethhena, Sri Lanka
}

Date Received: 11-12-2013 Date Accepted: 23-04-2014

\begin{abstract}
Problems generated by solid waste have become a major national issue in Sri Lanka due to high levels of economic growth and consumption. Inappropriate management of solid waste may generate many problems such as environmental pollution, public health, social and economic problems as well as aesthetic issues. Therefore, this problem needs immediate attention not only for the management of waste, but also for the study of individual behavior related to solid waste production and use. This research was carried out as a case study in Kalutara Urban Council area, where behavior that is related to the production and management of waste is analysed. To achieve this, a questionnaire survey was conducted for the households of Kalutara North, Kalutara South and Katukurunda. The households' descriptive, inferential and informative believes were identified where they express agreement or disagreement regarding the final disposal of waste. In total 100 households completed the questionnaire. This work approached the behavioral aspect of the problem by considering the attitudes towards the environment and the beliefs about the environment. In addition, knowledge of environment and the problems raised have been considered for prediction of environmentally protective behavior. In this investigation, the classification of believes were considered in terms of austerity or limitation of consumption, conservation and material beliefs or material squandering. Further, the environmental attitudes were considered as emotional, cognitive (know) and behavioral. Based on the preliminary results of this study, it can be concluded that believes and attitudes show a certain level of relation with the behavior of the households. The questionnaire survey was useful to highlight the solid waste problem that exists in the area and to indicate the trends of attitudes and behavior among the solid waste management. Further, by considering the findings of this study, an environmental education program to promote pro-environmental behavior in solid waste management must be established to change non-effective waste management practices and to promote the households to use the waste as a resource.
\end{abstract}

Key words: individual behavior, environmental attitudes, Kalutara Urban Council, proenvironmental behavior, solid waste management

\footnotetext{
*Correspondence: sajeewani21@yahoo.com

Tel: +94714835475

ISSN 2235-9370 Print/ISSN 2235-9362 Online @ C University of Sri Jayewardenepura
} 


\section{Introduction}

The problem of solid waste has become a global issue due to rapid industrialisation and population growth. The solid waste has great diversity of material composition and not only rising its quantity, but also changing its composition regularly. Thus, it causes many problems in environmental, social and economic aspects. The work on solid waste management has two approaches namely, technical approach and behavioral approach. Since, this paper mainly investigates the pro-environmental behavior which concern positive attitudes and beliefs of households in Kalutara Urban Council area regarding the behavior on solid waste production and management.

Kalutara town is about $40 \mathrm{~km}$ away from Colombo and close to the Southern expressway and coastal railway line. The average annual growth rate of Kalutara district has been increased at the rate of $1.26 \%$ from $1981-2001$ and $1.23 \%$ from $2001-2012$.

According to the census of population and housing by the department of Census and Statistics (2001), the highest population of 37,081 was recorded in the Kalutara Urban Council. The Kalutara Urban Council which consists of 11 wards had highest population in hospital ward accounting 5,235.

Due to the high population in this area and lack of infrastructure facilities in the authorities, the proper solid waste collection is difficult. The un-segregated waste is taken to the Nagoda, Pohorawatta 'Mihisaru' compost preparing centre which was under Western Province Waste Management Authority and Central Environmental Authority. However, recently the compost plant has taken action to collect only the bio-degradable waste by the Urban Council, while other non-biodegradable waste are dumped in to an open dumpsite belonging to the Kalutara Urban Council. Hence, the Urban Council has requested households to segregate waste into bio-degradable waste, plastic and polythene, cardboard and paper, and glass waste and the collection plan was commenced from $1^{\text {st }}$ May 2013. However, many complaints have arisen that the collection is not properly done as scheduled and authorities have refused to collect plastic and polythene from households. Due to this unsatisfactory schedule, households inspired to burn nonbiodegradable waste which causes health hazards by inhalation of contaminated toxins and smoke from burning.

The positive behavior or pro-environmental behavior against solid waste management on quality of life cannot be over-emphasised. As such, this study aims to observe the household behavior to patronise the local government and other agencies on the need of better solid waste management practices.

In the case of behavioral aspect of the problem, it is vital to consider household participation in management and production of solid waste. Number of studies has been done regarding this (Anand, 1999; Fuentes et al., 2000) which emphasize the importance of household participation in waste-reduction programmes. Further, pro-environmental behavior has been studied by Borden and Schettino (1979) and Newhouse (1990). Attitudes towards the environment have been studied as predictive dispositional variables of pro-environmental behavior (Ojeda \& de Vega, 2003). As such, knowledge of the environment has been considered as a potential predictor of environmentally protective behavior (Blum, 1987; Schan \& Holzer, 1990).

In addition, the beliefs about environment have been studied by various researchers (Cary, 1993). One of the most interesting pro-environmental behaviour is comprised by conservation 
practices (Ojeda \& de Vega, 2003). It includes practices like reduction in energy consumption, reuse, and recycling (Ebreo \& Vinning, 1994).

Since the objective of the study is to identify the pro-environmental behavior of households in production and management of solid waste in this study reuse and recycling were used as representative of conservation practices.

Ojeda \& de Vega (2003) had studied the beliefs as the term austerity. As such, we use the term limitation of consumption (austerity), conservation (optimising resources) and material beliefs. Material beliefs are defined as those which favor the needs of the household over the restrictions originated by situations.

\section{Methodology}

Two major local government areas are located in Kalutara town; Kalutara Urban Council area administrating concurrently with the Kalutara Pradeshiya Sabha. The study area consists of Kalutara North, Kalutara South and Katukurunda which is administrated by the Kalutara Urban Council. This study area was selected because it has the highest population of 37,081 (Department of Census \& Statistics, 2001) and it is the centre of administration.

The study used primary data. A questionnaire with two parts was distributed among households in the study area. One part is used for general data and the second part consists of a Likert scale. For this purpose it was divided into two categories; environmental beliefs (limitation of consumption/austerity, conservation and material beliefs) and environmental attitudes (emotional, cognitive or knowledge, and behavioral). A total number of 100 households were sampled. This study would have benefitted from a higher sample size. However, due to lack of funds the sample size could not be increased. Descriptive statistics such as mean, and standard deviation were used for the analysis.

\section{Results and Discussion}

The Likert scale was used to calculate the mean and the standard deviation. Eight variables were used to determine the environmental beliefs while ten variables were used to determine environmental attitudes. The mean indicates the agreement or disagreement level to the statement presented in the sub-scale. When the sub-scale of each variable, 1 is total disagreement, 2 is disagreement, 3 is undecided, 4 is agreement, and 5 is total agreement.

The results with the central tendency numbers with environmental beliefs are listed in Table 1. The variables of this table are arranged according to 3 sub-scales. Variables 7 and 8 are negative while other variables are positive. The analysed numbers (mean) are rounded to the closest full number i.e. 3.53 into 4 and 3.49 into 3.

According to the results of limitation in consumption households show agreement in both variables. It shows that households believe that they should consume only the necessary things which will reduce the waste generation. In relation with the conservation beliefs variable 3 shows undecided while variable 4 and 5 show agreement with statements. It clearly shows that householders believe that reusing objects and separation of waste is a good practice to reduce waste. 
Table 1: Sub-scale of pro-environmental beliefs of the households in Kalutara Urban Council.

\begin{tabular}{lcc}
\hline Sub-scale variables & Mean & $\begin{array}{c}\text { Standard } \\
\text { Deviation }\end{array}$ \\
\hline $\begin{array}{l}\text { Limitation of consumption/ austerity } \\
\text { 1. Reducing waste is a good alternative that favors the environment. }\end{array}$ & 4.24 & 0.90 \\
2. I should consume only the necessary things for me. & 4.06 & 1.04 \\
\hline $\begin{array}{l}\text { Conservation } \\
\text { 3. Reusing waste means that using any object by avoiding it to be trash. }\end{array}$ & 3.21 & 1.10 \\
4. Reusing is a part of the waste management and is an alternative & 3.95 & 0.96 \\
which favors the environment. & & \\
5. Separation of waste reduces waste generation. & 3.67 & 1.08 \\
\hline $\begin{array}{l}\text { Material beliefs } \\
\text { 6. Recycling is an alternative of waste management and it favors the }\end{array}$ & 4.01 & 1.00 \\
Environment. & & \\
7. Disposable products are indispensable in day to day life. & 2.47 & 1.18 \\
8. Reduction of waste generation may reduce the comfort of life. & 2.69 & 1.11 \\
\end{tabular}

Table 2 shows the results with central tendency numbers of variables of the each subscale in environmental attitudes. The construction method of the scale is similar to Table 1. The positive variables of the sub-scale are 1,5 and 8 .

Table 2: Sub-scale of pro-environmental attitudes of the households in Kalutara Urban Council.

\begin{tabular}{lcl}
\hline Sub-scale variables & Mean $\begin{array}{l}\text { Standard } \\
\text { Deviation }\end{array}$ \\
\hline
\end{tabular}

Emotional

1. I feel angry when my neighbors throw waste in surrounding. $\quad 3.68 \quad 1.19$

2. It is a good practice if someone throws waste in any place. $\quad 1.67 \quad 0.91$

Cognitive (know)

$\begin{array}{lll}\text { 3. Waste in any place has no adverse effect to anyone. } & 1.72 & 0.90\end{array}$

4. Waste problems are just local authority problems. $\quad 2.16 \quad 1.24$

5. Waste is a great problem for the environment. $\quad 4.07 \quad 1.27$

$\begin{array}{lll}\text { 6. Waste generation without control doesn't harm anyone. } & 2.12 & 1.24\end{array}$

Behavioral

7. I need a lot of effort to segregate waste. $\quad 2.57 \quad 1.14$

8. When someone throws waste everywhere, I take his/her attention. $\quad 3.29 \quad 1.04$

9. When I saw someone throws garbage in any place, I generally do the $\quad 1.75 \quad 1.15$ same.

10. I am reluctant to pick up the waste which is spread out of the bin. $\quad 1.93 \quad 1.21$

According to the results of Table 2, it shows that in emotional, cognitive and behavioral attitudes of households are agreed when the variable subscale statement is positive (1 and 5) and disagreed when it is negative (2, 3, 4, 6, 7, 9 and 10) except in statement 8 in behavioral attitudes 
which shows undecided. Hence, this shows that there is a resemblance between how households behave, and what they know with their emotions against waste management. The undecided statement 8 means the householders are reluctant to interfere or take action against someone who indiscriminate discharge of waste.

\section{Conclusions}

The preliminary study showed that beliefs of households including limitation of consumption (austerity), conservation by reuse and recycling have positive consequence on proenvironmental behavior. However, considering material beliefs, households are in doubt of limiting consumption that might reduce their comfort in life. According to the results of attitudes of households it is observed that there is congruence between behavior, emotions and knowledge against waste management. Further, by considering the findings of this study, an environmental education program to promote pro-environmental behavior in solid waste management must be established to change non-effective waste management practices and to promote the householders to use the waste as a resource.

\section{References}

Anand, P.B., 1999. Waste Management in Madras revisited. Environment \& Urbanization, 11(2):161-176.

Blum, A., 1987. Student's knowledge and beliefs concerning environmental issues in four countries. Journal of Environmental Education, 18:7-13.

Borden, R.J., Schettino, A.P., 1979. Determinants of environmentally responsible behavior. Journal of Environmental Education, 10:35-39.

Cary, J., 1993. The nature of symbolic beliefs and environmental behavior in a rural setting. Environment \& Behavior, 25:555-576.

Census 2012 Results on Population, Dept. of Census \& Statistics, http://www. statistics.gov.lk/ PopHou Sat/CPH2011/Accessed 12 June 2013.

Ebreo, A., Vinning, J., 1994. Conservation-wise consumers: Recycling household shopping as ecological behavior. Journal of Environmental Systems, 23:109-131.

Fuentes,V.R., Silva, K.H., and Ojeda, B.S., 2000. Environmental Engineering and Health Sciences. Proposal of an environmental Conscience to reduce the generation of Domicilary solid waste at one urban community. Water Resources Publications, LCC, pp.371-378.

Newhouse, N., 1990. Implications of attitude and behavior research for environmental conservation. Journal of Environmental Education, 22:26-32.

Ojeda B.S., de Vega, C.A., 2003. Pro-environmental behavior regarding solid waste management in students from the Mexico-United States border region. Web. http://www.sciencedirect.com/science/ article/pii/ S0921344903000284, Accessed 14 June 2013.

Schan, J., Holzer, E., 1990. Studies of individual environmental concern. The role of knowledge, gender, and background variables. Environment \& Behavior, 22:767-786. 